\title{
Frequency of overweight/obesity among a group of children with celiac disease in Iran
}

\author{
Touran Shahraki ${ }^{1}$, Mansour Shahraki², Ivor D. Hill ${ }^{3}$ \\ ${ }^{1}$ Department of Pediatrics, Faculty of Medicine, Children and Adolescents Health Research Center, Resistant Tuberculosis \\ Institute, Zahedan University of Medical Science's, Zahedan, Iran \\ ${ }^{2}$ Department of Nutrition, Children and Adolescents Health Research Center, Resistant Tuberculosis Institute, Zahedan \\ University of Medical Science's, Zahedan, Iran \\ ${ }^{3}$ Department of Pediatrics, The Ohio State University School of Medicine, Nationwide Children's Hospital, Columbus, OH, USA
}

Gastroenterology Rev 2018; 13 (2): 127-131

DOI: https://doi.org/10.5114/pg.2018.73347

Key words: pediatrics, obesity, body mass index, celiac disease, overweight. Address for correspondence: Touran Shahraki, Department of Pediatrics, Faculty of Medicine, Children and Adolescents Health Research Center,
Resistant Tuberculosis Institute, Zahedan University of Medical Science's, Zahedan, Iran, phone: +985433295575 , fax: +98 54 33447092, e-mail: dr_tshahraki@yahoo.com

\begin{abstract}
Introduction: A small number of overweight and obese children with celiac disease (CD) has been reported.

Aim: To estimate the prevalence of obesity, underweight and normal weight in a group of Iranian pediatric patients.

Material and methods: In a retrospective study from 2007 to 2015, 225 children less than 18 years old with biopsy-proven CD were enrolled. Data collected included demographic characteristics, clinical presentation, antibody titers and severity of small-bowel mucosal damage. Body mass index (BMI) profile of subjects was calculated based on the age and gender percentile at presentation.

Results: The mean \pm standard deviation (SD) for age was $7.4 \pm 3.8$ and $62 \%$ of patients were female. Fifty-four percent of patients presented with a normal BMI, $43 \%$ were underweight, and the remaining patients (3.5\%) were overweight/obese. The mean age of underweight and normal weight patients was higher than that of obese/overweight patients. Mean \pm SD of TTG titer was higher in overweight/obese and normal weight children compared to underweight subjects. The majority of patients $(195 / 225)$ had severe enteropathy compatible with Marsh III on duodenal biopsy. Most of the children had gastrointestinal (GI) and extra-intestinal manifestations on presentation. There was no association between severity of histological disease and BMI for age. Five out of eight cases in the obese/overweight group had an index case with CD in their family.

Conclusions: This study highlights the importance of considering celiac disease in children regardless of their BMI. Failure to diagnose $C D$ in children leads to unnecessary diagnostic delays and long-term adverse health consequences.
\end{abstract}

\section{Introduction}

Celiac disease (CD) is an autoimmune enteropathy characterized by small intestinal villous atrophy induced by gluten ingestion and requires lifelong treatment with a gluten-free diet [1]. The availability of serological screening tests has enhanced awareness of the condition and revealed that about $1 \%$ of the general population is affected by CD [2]. Children may present with the classical picture of disease characterized by chronic diarrhea, failure to thrive (FTT) and abdominal distention or with non-classical features including gastrointestinal symptoms as well as extra-intestinal manifestations. Additional asymptomatic cases have been identified on the basis of screening people who are at increased risk for the condition [3].
Because CD causes damage to the small intestinal mucosa it can be expected to result in malabsorption of nutrients leading to poor weight gain, weight loss and undernutrition. However, a number of recent reports have identified an increasing number of adults, adolescents and children who are overweight, or even obese, at the time of initial diagnosis of CD [4-6]. This trend coincides with the rising prevalence of overweight and obese people in the general population in many developed countries as well as in Iran [7, 8].

\section{Aim \\ There are no studies describing the coexistence of $\mathrm{CD}$ and overweight/obesity in Iranian children. The pri-}


mary aim of this study was to determine the frequency of obesity/overweight in children with $C D$ at the initial diagnosis and describe the clinical and pathological characteristics of this group. A secondary aim was to report the relative frequency of normal $B M I$ and under-nutrition in children with CD in south-east Iran.

\section{Material and methods}

Medical records of all children with $C D$ seen in a tertiary-care teaching hospital by a pediatric gastroenterologist in south-east Iran over a 9-year period from 2007 to 2015 were reviewed. All subjects less than 18 years old and with biopsy-proven diagnosis of CD were enrolled in the study. Data collected from the medical records included demographic characteristics, anthropometric data, and clinical features at diagnosis, celiac antibody titers and severity of small-bowel mucosal damage. Children with incomplete data were excluded from the study.

Weight, height and body mass index (BMI) of children were calculated based on age and gender percentiles from growth charts published by the Centers for Disease Control and Prevention [9]. For subjects $<2$ years, weight-for-height percentiles were used instead of BMI. Children with a BMI for age $<5^{\text {th }}$ percentile were considered underweight, those with a BMI between the $5^{\text {th }}$ and $85^{\text {th }}$ percentile for age were considered normal weight, and those with a BMI between the $85^{\text {th }}$ and $95^{\text {th }}$ percentile for age and $>95^{\text {th }}$ percentile for age were classified as overweight and obese, respectively [10].

TTG IgA and total IgA were determined by a commercial ELISA kit (Aeskulisa, Germany) and Bionik-immunoturbidimetric Assay, Tehran (Iran), respectively. TTG IgA titers of $<12 \mathrm{U} / \mathrm{ml}$ were regarded as negative, $12-18 \mathrm{U} / \mathrm{ml}$ as borderline and $>18 \mathrm{U} / \mathrm{ml}$ as positive. In cases with IgA deficiency a serological test for TTG-IgG was requested. All patients had small intestinal mucosal biopsies for evaluation of the grade of villous damage using the modified Marsh grading [11]. Diagnosis of CD was considered confirmed by compatible serologic tests, characteristic small bowel intestinal histology and response to a gluten-free diet according to the ESPGHAN criteria [12]. Those with Marsh II or III changes were diagnosed with CD [1].

All participants had written informed consent from their parents or guardian. The study was approved by the Ethics Committee of the Zahedan Medical University of Sciences and Research Center for Children and Adolescent Health.

\section{Statistical analysis}

Data were analyzed by descriptive analysis using SPSS 18 (Chicago, SPSS Inc). The results are presented as mean \pm standard deviation and proportion. At first normality of data was checked by the Shapiro-Wilk test. The $\chi^{2}$ test, one-way ANOVA test and Kruskal-Wallis test were used for comparison between groups. The $\chi^{2}$ test was used for comparison of gender and Marsh classification with BMI to compare categorical data. The ANOVA test was used to assess the relation between age and TTG titer with BMI. $P$-values $<0.05$ are considered statistically significant.

\section{Results}

Of the 225 children with CD, 121 (54\%) presented with a normal BMI, 96 (43\%) were underweight and only $8(3.5 \%)$ were overweight/obese at the time of diagnosis. The mean \pm SD for age was $7.4 \pm 3.8$ and 139 (62\%) were female. A predominance of females to males was found in all three weight categories although this did not reach statistical significance. Seventy-five (33\%) subjects were $0-5$ years of age, 111 (49\%) were 6-11 years old and 39 (17\%) were adolescents (12-18 years). The mean age of the underweight and normal weight children was higher than that of obese and overweight children $(7.9 \pm 3.8$ and $7.1 \pm 3.8$ vs. 5.7 \pm 2.6 , Table I) but the difference between groups was not significant. There was a significant difference between BMI profile and TTG titer as the mean \pm SD TTG titer was higher in overweight/obese and normal weight children compared to underweight subjects. The majority of patients (195/225) had severe enteropathy compatible with Marsh III on duodenal biopsy and the remaining cases $(30 / 225)$ had Marsh II. There was no association between severity of histological disease (classified by Marsh score) and BMI for age (Table I). Most of the children had gastrointestinal and extra-intestinal manifestations on presentation. A small number of children were asymptomatic.

Of those with overweight/obesity (8 cases), 6 were female, 4 were overweight and 4 were obese. All of the children in this group had $>4$ times the upper limit of TTG IgA. All of the children had biopsy results compatible with Marsh III ( 5 cases had Marsh 3a, 1 case had $3 b$ and 2 subjects had Marsh $3 c$ ). The majority of the overweight/obese children belonged to groups at high risk for CD (5 cases) and 3 cases were checked due to their symptoms (Table II). The GI and extra-GI manifestations in the overweight/obese children are shown in Table II. Two children had no symptoms; one was a sibling of a child with CD and the other had diabetes type 1 .

\section{Discussion}

Coexistence of obesity and celiac disease in children has been reported recently. Although we identi- 
Table I. Body mass index percentile of children with celiac disease by age, gender, TTG titer and Marsh classification

\begin{tabular}{|c|c|c|c|c|}
\hline Parameter & $\begin{array}{l}\text { Underweight } \\
(n=96)\end{array}$ & $\begin{array}{c}\text { Normal weight } \\
(n=121)\end{array}$ & $\begin{array}{l}\text { Overweight/obese } \\
\qquad(n=8)\end{array}$ & $P$-value \\
\hline \multicolumn{5}{|l|}{ Gender: } \\
\hline Female (139) & $58(42 \%)$ & 75 (54\%) & $6(4 \%)$ & \multirow[t]{2}{*}{$0.7^{\star}$} \\
\hline Male (86) & $38(44 \%)$ & $46(53.5 \%)$ & $2(2 \%)$ & \\
\hline Age (mean \pm SD) [years] & $7.9 \pm 3.8$ & $7.1 \pm 3.8$ & $5.7 \pm 2.6$ & $0.1^{\star *}$ \\
\hline TTG-IgA titer (mean \pm SD) & $124 \pm 124$ & $147 \pm 180$ & $235 \pm 140$ & $0.04^{* *}$ \\
\hline \multicolumn{4}{|l|}{ Marsh: } & \multirow[t]{3}{*}{$0.1^{*}$} \\
\hline II (30) & $17(57 \%)$ & $13(43 \%)$ & 0 & \\
\hline III (195) & $79(40 \%)$ & $108(55 \%)$ & $8(4 \%)$ & \\
\hline \multicolumn{4}{|l|}{ Clinical symptoms: } & \multirow[t]{4}{*}{$0.06^{*}$} \\
\hline Gl & 72 & 87 & 5 & \\
\hline Extra-Gl & 22 & 23 & 1 & \\
\hline Asymptomatic & 2 & 11 & 2 & \\
\hline
\end{tabular}

${ }^{*} \chi^{2},{ }^{* *} A N O V A$ and Kruskal-Wallis test.

Table II. Characteristics of overweight and obese children with celiac disease

\begin{tabular}{cccccccc} 
No. & Gender & $\begin{array}{c}\text { Age } \\
\text { [years] }\end{array}$ & BMI percentile & $\begin{array}{c}\text { TTG } \\
\text { titer }\end{array}$ & $\begin{array}{c}\text { Marsh } \\
\text { grade }\end{array}$ & Clinical presentation & Diabetes \\
\hline 1 & $F$ & 2.4 & 86 & 220 & $3 b$ & Diarrhea, distention \\
\hline 2 & $F$ & 4 & 88 & 110 & $3 c$ & Diarrhea, distention, AP Hx of intussusception \\
\hline 3 & M & 4 & 98 & 200 & $3 c$ & Diarrhea, distention \\
\hline 4 & $F$ & 9 & 97 & 73 & $3 a$ & AP \\
\hline 5 & $F$ & 9 & 86.7 & 174 & $3 a$ & AP \\
\hline 6 & M & 3 & 99.5 & 267 & $3 a$ & Asymptomatic \\
\hline 7 & $F$ & 6.7 & 90 & 310 & $3 a$ & Asymptomatic \\
\hline 8 & $F$ & 7.7 & 97.4 & 525 & $3 a$ & Bone pain, early puberty \\
+++
\end{tabular}

FM - family member with celiac disease, AP-abdominal pain. *Siblings.

fied some overweight/obese children with CD in Iran, this number was relatively small and the majority were either of normal weight or underweight.

The relatively high frequency of underweight children with CD in Iran is similar to that found in other developing countries such as India and Turkey [13, 14]. This is in contrast to many developed countries, where the prevalence of undernutrition in children with $C D$ has decreased to $4-5 \%[15,16]$, indicating that malnutrition is no longer a common presentation $[17,18]$. As demonstrated in Table III, there are now many reports showing that more than $50 \%$ of newly diagnosed children with CD have a normal BMI [13, 14, 16, 19-21]. In a study of 143 American children aged 13 months to 19 years, $74.5 \%$ had a normal BMI, which is similar to that of children in Sweden, where $72.8 \%$ had normal weight $[16,19]$. Therefore, normal body weight in children with $\mathrm{CD}$ is a common finding and the BMI is not a reliable indicator for predicting CD in children [16].

In our study the underweight children were generally older at the time of diagnosis than those of normal or excess weight, suggesting perhaps that delay in diagnosis may be associated with poor weight gain or weight loss. It is also likely that the poor growth of the children in this study could be due to poor socioeconomic circumstances in the region [22, 23]. Regardless of the cause, early detection of CD by means of liberal use of serological tests is essential in order to minimize 
Table III. Comparison of prevalence of overweight/obesity in other studies with present study

\begin{tabular}{|c|c|c|c|c|c|c|}
\hline Author [ref.] & Year & Age & No & Underweight (\%) & $\begin{array}{l}\text { Normal weight } \\
\text { (\%) }\end{array}$ & $\begin{array}{c}\text { Overweight/ } \\
\text { obese (\%) }\end{array}$ \\
\hline Reilly [19] & 2011 & 13 months - 19 year & 142 & 6.5 & 74.5 & 18.6 \\
\hline Venkatasubramani [5] & 2010 & $1-17$ years & 143 & $?$ & $?$ & 5 \\
\hline Singh [13] & 2016 & Adolescents, adults & 210 & 36.2 & 54.8 & 9.1 \\
\hline Valletta [15] & 2010 & Children & 149 & 5 & 81 & 14 \\
\hline Brambilla [20] & 2013 & $2-16$ years & 150 & 16 & & 12 \\
\hline Norsa [21] & & $10.4 \pm 4.1$ years & 114 & 9.6 & 76.3 & 14 \\
\hline van der Pals [16] & 2014 & 12 years & 239 & 4.2 & 82.0 & 13.8 \\
\hline Gokce [14] & 2015 & $8.14 \pm 4.38$ years & 191 & 22.5 & 69.6 & 5.8 \\
\hline Present study & 2017 & $7.4 \pm 3.8$ years & 225 & 43 & 54 & 3.4 \\
\hline
\end{tabular}

the potential for adverse effects of $C D$ on the nutritional status in children.

There are several reports noting the presence of obesity at the time of diagnosis of CD. In adults the prevalence of overweight/obesity has ranged from $0.45 \%$ to $39 \%$ while in children it has ranged from $5 \%$ to $21 \%[5,24-26]$. In our population the prevalence of children who were overweight/obese at the time of the initial diagnosis was lower than reported elsewhere and was only $3.4 \%$ [24]. Given that CD is a disorder that causes damage to the intestinal mucosa, one would not expect the condition to be associated with excess weight gain.

The reason for obesity in children with $C D$ despite the potential for malabsorption is not clear. Possible explanations include compensatory absorption of nutrients in the distal small bowel due to villous hypertrophy [24], increasing prevalence of obesity in the general population with an effect on the prevalence of other diseases [27], or a deficiency of iron and micronutrients in patients with $C D$, which might cause an increase in food craving [28]. Regardless of the cause, it is essential that physicians appreciate the fact that overweight/ obese children can have CD, as failure to do so could lead to diagnostic delays with potential for adverse health consequences.

Although the overweight/obese children in this series were slightly younger at diagnosis than those with normal or low weight, this difference was not significant, and there was also no difference between the groups with regards to gender or histological grading. The majority of the overweight/obese children were females (6/8), which differs from some studies that report a predominance of boys with $C D$ who are overweight. An interesting observation is that the children in the overweight/obese group had significantly higher levels of TTG-IgA antibodies than the other two groups. The reasons for this finding are unclear.

There are studies that have shown lower antibody titers in patients with failure to gain weight and higher antibody titers in diabetic patients [29], but to the best of our knowledge higher levels in overweight/obese children with CD have not been described before.

One other finding in our study was the association of CD with other autoimmune diseases such as diabetes type 1 , which highlights the need for screening as well as correction of nutritional requirements for this population [30, 31].

Our study has some limitations. Because it was a retrospective study from a tertiary referral center in the south-east of Iran, it may not be reflective of other provinces in Iran. In addition, the low numbers of children with overweight/obesity in this study mask any significant clinical characteristics that distinguish these children from those who are normal or underweight. Nevertheless, this is the first study reporting the prevalence of overweight/obesity in Iranian children and serves to alert physicians to consider a diagnosis of CD in symptomatic children regardless of their nutritional status at the time of presentation.

\section{Conclusions}

This study highlights the importance of considering a diagnosis of $C D$ in children with symptoms associated with the condition even when they are overweight/ obese. Failure to do so can lead to unnecessary diagnostic delays and place children at risk for long-term adverse health consequences.

\section{Acknowledgments}

We thank all participants of this study. 


\section{Conflict of interest}

The authors declare no conflict of interest.

\section{References}

1. Husby S, Koletzko S, Korponay-Szabó IR, et al. European Society for Pediatric Gastroenterology, Hepatology, and Nutrition guidelines for the diagnosis of coeliac disease. J Pediatr Gastroenterol Nutr 2012; 54: 136-60.

2. Catassi C, Anderson RP, Hill ID, et al. World perspective on celiac disease. J Pediatr Gastroenterol Nutr 2012; 55: 494-9.

3. Ludvigsson JF, Leffler DA, Bai JC, et al. The Oslo definitions for coeliac disease and related terms. Gut 2013; 62: 43-52.

4. Dickey W. Joint BAPEN and British Society of Gastroenterology Symposium on coeliac disease: basics and controversies. Coeliac disease in the twenty-first century. Proc Nutr Soc 2009; 68: 234-41.

5. Venkatasubramani N, Telega G, Werlin SL. Obesity in pediatric celiac disease. J Pediatr Gastroenterol Nutr 2010; 51: 295-7.

6. Balamtekin N, Demir H, Baysoy G, et al. obesity in adolescents with celiac disease: two adolescents and two differentpresentations. Turk J Pediatr 2011; 53: 314-6.

7. Esmaili H, Bahreynian M, Qorbani M, et al. Prevalence of general and abdominal obesity in nationally representative sample of Iranian children and adolescents: the CASPIAN-IV Study. Iran J Pediatr 2015; 25: e401.

8. Skinner AC, Perrin EM, Skelton JA. Prevalence of obesity and severe obesity in US children, 1999-2014. Obesity (Silver Spring) 2016; 24: 1116-23.

9. Kuczmarski RJ, Ogden CL, Guo SS, et al. 2000 CDC Growth Charts for the United states: methods and development. Vital Health Stat 11. 2002; 246: 1-190.

10. Grummer-Strawn LM, Flegal KM, Grummer-Strawn LM, et al. CDC growth charts: United States. Adv Data 2000; 314: 1-27.

11. Oberhuber G, Granditsch G, Vogelsang H. The histopathology of coeliac disease: time for a standardized report scheme for pathologists. Eur J Gastroenterol Hepatol 1999; 11: 1185-94.

12. Walker-Smith JA, Guandalini S, Schmitz J, et al. Revised criteria for diagnosis of celiac disease. Report of Working Group of European Society of Paediatric Gastroenterology and Nutrition. Arch Dis Child 1990; 65: 909-11.

13. Singh I, Agnihotri A, Sharma A, et al. Patients with celiac disease may have normal weight or may even be overweight. Indian J Gastroenterol 2016; 35: 20-4.

14. Gokce $S$, Arslantas E. Changing face and clinical features of celiac disease in children. Pediatr Int 2015; 57: 107-12.

15. Valletta E, Fornaro M, Cipolli M, et al. Celiac disease and obesity: need for nutritional follow-up after diagnosis. Eur J Clin Nutr 2010; 64: 1371-2.

16. van der Pals M, Myléus A, Norström F, et al. Body mass index is not a reliable tool in predicting celiac disease in children. BMC Pediatr 2014; 14: 165

17. Rampertab SD, Pooran N, Brar P, et al. Trends in the presentation of celiac disease. Am J Med 2006; 119: 355.e9-14.

18. Telega G, Bennet TR, Werlin S. Emerging new clinical patterns in the presentation of celiac disease. Arch Pediatr Adolesc Med 2008; 162: 164-8.
19. Reilly NR, Aguilar K, Hassid BG, et al. Celiac disease in normal-weight and overweight children: clinical features and growth outcomes following a gluten-free diet. J Pediatr Gastroenterol Nutr 2011; 53: 528-31.

20. Brambilla P, Picca M, Dilillo D, et al. Changes of body mass index in celiac children on a gluten-free diet. Nutr Metab Cardiovasc Dis 2013; 23: 177-82.

21. Norsa L, Shamir R, Zevit N, et al. Cardiovascular disease risk factor profiles in children with celiac disease on gluten-free diets. World J Gastroenterol 2013; 19: 5658-64.

22. Shahraki T, Hill ID. Clinical spectrum of celiac disease in children in Sistan and Baluchestan Province. Arch Iran Med 2016; 19: 762-7.

23. Shahraki T, Hill I. Prevalence of celiac disease in first-degree relative of children in Sistan and Baluchestan province (Iran). J Dig Dis 2016; 17: 685-91.

24. Nenna R, Mosca A, Mennini M, et al. Coeliac disease screening among a large cohort of overweight/obese children. J Pediatr Gastroenterol Nutr 2015; 60: 405-7.

25. Aurangzeb B, Leach ST, Lemberg DA, et al. Nutritional status of children with coeliac disease. Acta Paediatr 2010; 99: 1020-5.

26. Montazerifar F, Karajibani M, Rakhshani F, et al. Prevalence of underweight, overweight and obesity among high-school girls inSistan va Baluchistan. East Mediterr Health J 2009; 15: 1293-300.

27. Phatak UP, Pashankar DS. Obesity and gastrointestinal disorders in children. J Pediatr Gastroenterol Nutr 2015; 60: 441-5.

28. Murray JA, Watson T, Clearman B, et al. Effect of a gluten-free diet on gastrointestinal symptoms in celiac disease. Am J Clin Nutr 2004; 79: 669-73.

29. Aldaghi MA, Dehghani SM, Haghighat M. Evaluation of the correlation between tTG-IgA titer and duodenal biopsy findings in children with suspected celiac disease. Iran J Pediatr 2016; 26: e3615.

30. Szcześniak GR, Zdybel W, Kozak-Nurczyk P, et al. An evaluation of the prevalence of autoimmunological diseases in patients with diabetes and obesity hospitalized in the Department of Diabetology, Rural Medicine Institute in Lublin. Fam Med Prim Care Rev 2016; 18: 345-7.

31. Romańczuk B, Szaflarska-Popławska A, Chełchowska M, et al. Analysis of the concentration of vitamin $E$ in erythrocytes of patients with celiac disease. Gastroenterology Rev 2016; 11 : 282-5.

Received: 18.08 .2017

Accepted: 10.11.2017 